\title{
ТЕОРЕТИЧЕСКИЕ ОСНОВЫ РЕГУЛИРОВАНИЯ ЮРИДИЧЕСКОЙ ОТВЕТСТВЕННОСТИ ЗА НОВЫЕ ФОРМЫ ИНТЕРНЕТ- МОШЕННИЧЕСТВА В СЕТИ «ИНТЕРНЕТ»
}

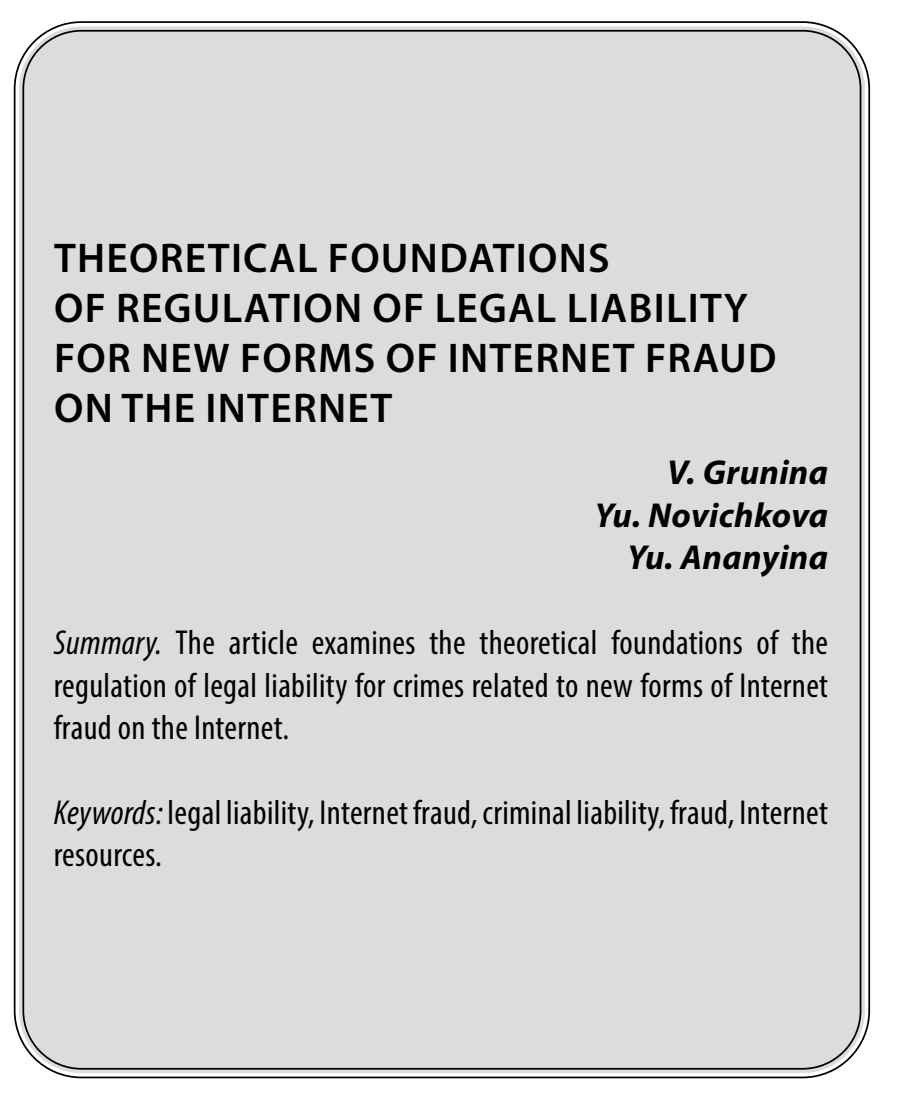

C еть «Интернет» становится пространством для совершения уголовно-наказуемых действий, которые в силу его виртуальности сложно определить, а мошенников - привлечь к реальной юридической ответственности. В Российской Федерации в 2020 году в период действия ограничений, введенных из-за распространения коронавирусной инфекции резко, по сравнению с 2019 годом, выросло число зарегистрированных случаев мошенничества. Об этом свидетельствует статистика Генпрокуратуры, проанализированная РБК. При этом рост произошел исключительно за счет телефонного и интернет-мошенничества - за шесть месяцев 2020 года число случаев такого мошенничества выросло на 76\% по сравнению с первым полугодием 2019 года [1].

Юридическая ответственность за совершение какого-либо правонарушения, в том числе за преступления мошеннической направленности в сети «Интернет», является одной из наиболее фундаментальных и дис-
Грунина Вероника Александровна

К.ю.н., доцент, Владимирский филиал Российской академии народного хозяйства и государственной службы при Президенте Российской Федерации vgrunvgrun@rambler.ru

Новичкова Юлия Геннадьевна Старший преподаватель, Университет ФСИН России (Санкт-Петербург) 3590568@mail.ru

Ананьина Юлия Александровна

Н.с., Владимирский юридический институт ФСИН Poccuu petron@rambler.ru

Аннотация. В статье рассматриваются теоретические основы регулирования юридической ответственности за преступления, связанные новыми формами интернет-мошенничества в сети «Интернет».

Ключевые слова: юридическая ответственность, интернет-мошенничество, уголовная ответственность, мошенничество, интернет-ресурсы.

куссионных тем в юридической науке, требующей пристального внимания.

В юридической науке применительно к юридической ответственности не выработано универсального, единого подхода, что, бесспорно, осложняет ее изучение и восприятие. Существующие разногласия относительно данного вопроса, по мнению Скребневой Н.А. связаны, как с активными творческими поисками ученых, так и наличием различных видов юридической ответственности, а также разнообразием мнений на негативную и позитивную юридическую ответственность. Действительно, различные ученые-юристы по-разному понимают, что же такое юридическая ответственность. По мнению Наумова С.Ю., если все позиции ученых-юристов проанализировать, то можно выделить три основных мнения толкования юридической ответственности:

- юридическая ответственность - это обязанность виновного лица претерпеть определенные 
лишения личного, имущественного или организационного характера (меры государственного принуждения) за совершенное им правонарушение;

- юридическая ответственность - это правоотношение, возникающее между государством в лице его компетентных государственных органов или должностных лиц и правонарушителем, в рамках которого государство обладает правом налагать взыскания за совершенное правонарушение, а нарушитель несет обязанность эти взыскания претерпевать;

- юридическая ответственность - это мера государственного принуждения, которая применяются к правонарушителю за совершенное им правонарушение и содержат для него неблагоприятные последствия в виде лишений личного, имущественного или организационного характера государственными органами в жесткой процессуальной форме [2].

На основе анализа вышеуказанных определений можно выделить следующие признаки юридической ответственности:

- обеспечивается государственным принуждением;

- наступает исключительно за совершение правонарушения;

- устанавливается государством в правовых нормax;

- предполагает определённое наказание (лишение) для виновного лица;

- выступает формой реализации санкции правовой нормы в конкретном случае и применительно к конкретному лицу;

- налагается в определенном законом порядке и компетентными государственными органами [3].

Различные представители юридической науки выделяют достаточно схожие признаки юридической ответственности. Например, Н.С. Малеин считает, что юридической ответственности присущи три признака: обременение правонарушителя негативными ограничениями; отрицательная реакция на виновное деяние субъекта правонарушения; государственное принуждение.

Юридическая ответственность основывается на следующих принципах:

- законности (и преступное деяние, и его последствия установлены только в уголовном законе);

- равенства граждан перед законом (независимо от расы, возраста, национальности, должностного положения);
- вины (никто не может быть привлечен к ответственности за невиновное причинение вреда);

- справедливости (наказание должно быть соразмерно преступлению);

- гуманизма (не допускается причинение физических страданий и унижение человеческого достоинства).

В современной Российской Федерации юридическая ответственность подразделяется на различные виды. Разные ученые - юристы выделяют разное количество этих видов. Общепризнанным является разделение юридической ответственности на:

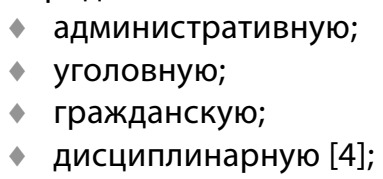

Кроме этого, выделяют еще материальную, конституционную, процессуальную, международную ответственность.

Основанием применения мер юридической ответственности является совершение лицом, достигшим возраста привлечения к юридической ответственности, противоправного деяния, запрещенного той или иной правовой нормой какой-либо отрасли права. Например, для привлечения к административной ответственности нужно совершить административное правонарушение, предусмотренное федеральным или региональным законодательством. В свою очередь для привлечения к дисциплинарной ответственности нужно совершить дисциплинарный проступок, предусмотренный трудовым законодательством или законодательством, которое заменяет трудовое для отдельной категории граждан (например, для гражданских служащих таким законодательством является Федеральный закон «О государственной гражданской службе Российской Федерации»).

Рассматривая вопросы ответственности за преступления мошеннической направленности в сети «Интернет» более подробно стоит говорить об одном из видов юридической ответственности - уголовной ответственности, так как юридическая категория «преступление» находится в рамках уголовного права.

Понятие уголовной ответственности часто используется в различных нормативных правовых актах, например, в статьях 1, 2 Уголовного кодекса Российской Федерации (далее - УК РФ), статьях 225, 461 Уголовно-процессуального кодекса Российской Федерации, однако его окончательное определение отсутствует. Юридическая наука этот пробел восполняет. 


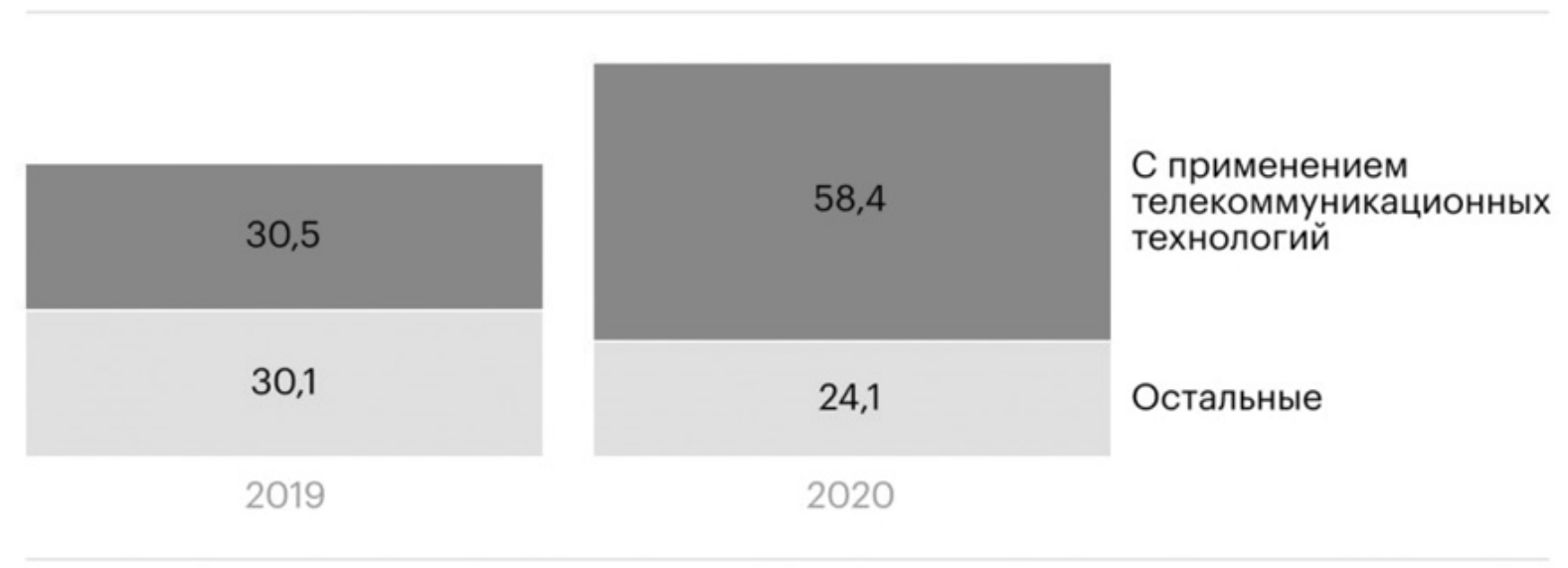

Рис. 1. Внутренняя структура мошенничества в Российской Федерации в 2020 году [6].

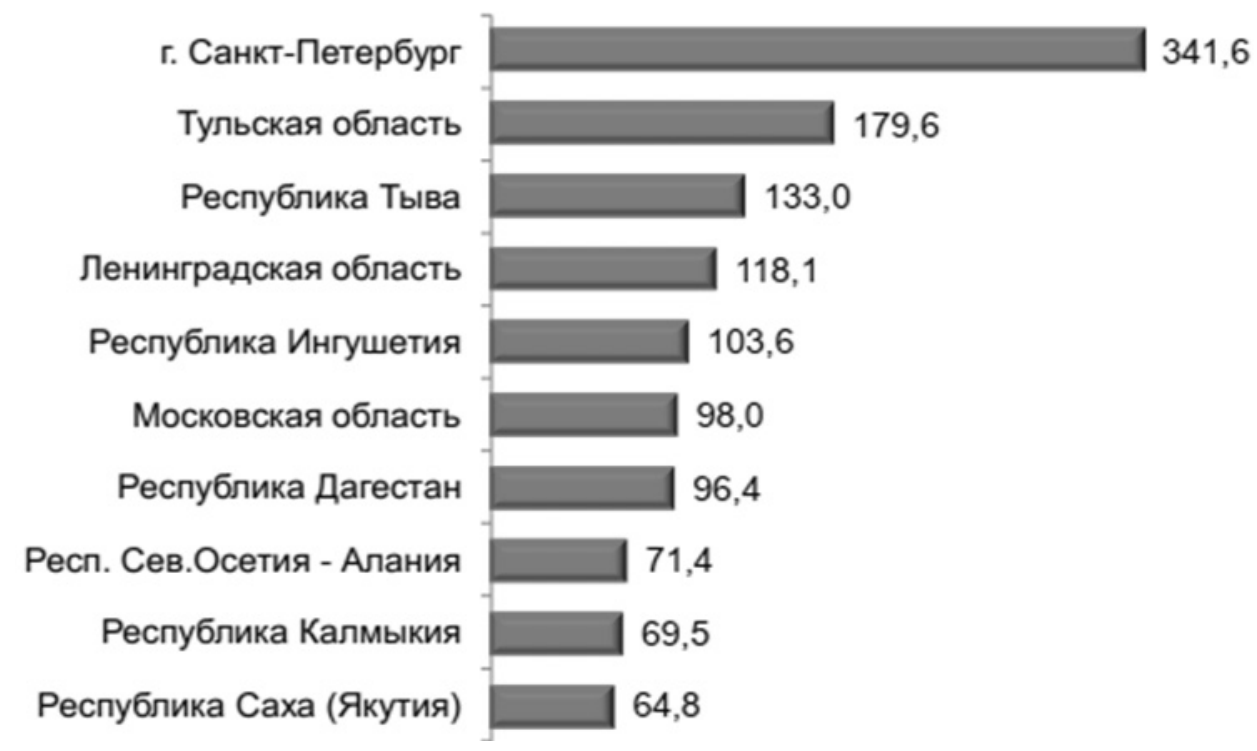

Рис. 2. Регионы с наибольшими темпами прироста зарегистрированных преступлений, совершенные с использованием информационно телекоммуникационных технологий или в сфере компьютерной информации [8].

По мнению А.И. Плотникова «уголовная ответственность - это принудительная мера уголовно-правового воздействия, применяемая государством к совершившему преступление лицу и выражающаяся в ограничении его правового статуса» [5]. Данному виду юридической ответственности присущи все те же признаки и принципы, что и другим видам юридической ответственности. Отличается лишь цель. В соответствие со статьей 44 УК РФ к таким целям относятся:

1. исправление лица, совершившего преступление;

2. предупреждение совершения осужденным новых преступлений (специальное предупреждение);
3. предупреждение совершения преступлений иными лицами (общее предупреждение).

Уголовная ответственность возникает как следствие совершения лицом преступления, понятие которого закреплено в ч. 1 ст. 14 УК РФ. Перечень таких деяний исчерпывающим образом предусмотрен в Особенной части УК РФ, но с развитием общественных отношений законодатель может его изменять. Преступления, в том числе и мошеннической направленности в сети «Интернет» не возникает и не совершается без причины, на пустом месте. Любое мошенничество, независимо в какой плоскости оно совершается, обладает рядом признаков: 
1. противоправность;

2. изъятие имущества;

3. причинение ущерба потерпевшему лицу;

4. прямой умысел на совершение противоправного деяния;

5. корыстный мотив преступника.

Применительно к преступлениям мошеннической направленности в сети «Интернет» самым главным признаком будет использование сети «Интернет» для совершения данного противоправного деяния.

В современной России наблюдается рост преступлений мошеннической направленности в сети «Интернет». Согласно отчету МВД о состоянии преступности в 2020 году в январе - декабре было зарегистрировано 510,4 тыс. преступлений, совершенных с использованием информационно телекоммуникационных технологий или на 73,4\% больше, чем за аналогичный период 2019 года. В общем числе зарегистрированных преступлений их удельный вес увеличился с 14,5\% в январе - декабре 2019 года до 25,0\%. В самой структуре мошенничества доля мошеннических действий, совершаемых с использованием сети «Интернет» преобладает над обычным мошенничеством. Данная тенденция идет уже несколько лет.

В январе-марте 2021 года было зарегистрировано 135,8 тыс. преступлений, совершенных с использованием информационно телекоммуникационных технологий или в сфере компьютерной информации, что на 33,7\% больше, чем за аналогичный период прошлого года. В общем числе зарегистрированных преступлений их удельный вес увеличился с 19,9\% в январе - марте 2020 года до 27,1\% [7]. Исходя из всех вышеуказанных статистических данных, мы видим, что происходит постоянный рост преступлений мошеннической направленности в сети «Интернет». Наиболее этот рост в 2021 году характерен для следующих регионов.

В чем же причина такого высокого роста преступлений мошеннической направленности в сети «Интернет»? На наш взгляд все эти причины можно разделить на две большие группы. Это обьективные причины, которые не зависят от человека и субъективные причины, которые прямо связаны с личностью преступника и личностью жертвы.

К числу обьективных причин можно отнести следующие:

- анонимность пользователей сети «Интернет».

Суть данной причины проявляется в том, что сеть «Интернет» гарантирует лицам почти $100-$ процентную анонимность, поскольку происхо- дит виртуальный контакт с жертвой, а не личный. Кроме этого, достаточно сложно вычислить места нахождения лица, которое совершает мошеннические действия, поскольку само оно может находиться в одном месте, а компьютер, смартфон и т.д. совершенно в ином.

- низкая стоимость и доступность сети «Интернет».

В настоящее время любой гражданин, который имеет компьютер, ноутбук, какой-либо гаджет может получить доступ в сеть «Интернет» относительно за небольшую плату в большей части мест на территории российского государства. Кроме этого, почти все общественные места (кафе, кинотеатры, парки, метро и другие места массового скопления) оснащены беспроводной сетью Wi-Fi, и при этом доступ к сети Интернет можно получить на безвозмездной основе, что упрощает жизнь мошенникам.

- оперативность действий, производимых в сети Интернет, которая сопровождается высокой скоростью распространения информации на всем пространстве сети, разрушая границы между какими - либо территориями.

- возможность охвата большой аудитории.

Суть данной причины состоит в том, что посредством использования сети «Интернет» можно охватить большое количество потенциальных жертв, находясь в одной месте и применяя минимум усилий для этого [9].

- высокая латентность преступлений, мошеннической направленности в сети «Интернет». Российские граждане, которые стали жертвой интернет-мошенника в силу разных причин не сообщают о данном факте в правоохранительные органы. К причинам такого поведения граждан можно, например, отнести недоверие к правоохранительной системе, уверенность в том, что это преступление останется не раскрытым, боязнь общественного осуждения и т.д. Такое положение дел приводит к тому, что преступники остаются безнаказанными и это толкает их на совершение новых и новых преступлений [10];

- многообразие и разнообразие способов совершения преступлений мошеннической направленности в сети «Интернет».

Как показывает практика, мошенники с каждым годом придумывают все новые и новые способы мошенничества. Законодатель и правоприменители не всегда успевают за этими общественными отношениями. Вследствие чего образуется правовой пробел, который временно нельзя заполнить никакой нормой права.

Что же касается субъективных причин преступлений мошеннической направленности в сети «Интер- 
нет», то условно все они подразделяются на две группы. Первая связана с личностью потерпевшей стороны, а вторая с личностью преступника.

1) Любое мошенничество, в том числе и с применением сети «Интернет», направлено на получение и извлечение материальной выгоды путем обмана потерпевшей стороны и злоупотребления его доверием. Основным моментом в мошенничестве выступает то, что лицо само принимает решение о передачи своих материальных благ мошеннику. Для непосредственного совершения мошеннического действия преступнику необходимо установить контакт с жертвой с использованием возможностей сети «Интернет». Вследствие этого личность потерпевшего, его психологические качества, жизненный опыт будут играть большую роль при совершении в отношении него мошенничества.

Ученые - криминологи, (Н.В. Сплавская, И.И. Пумшин) изучая личности лиц, которые стали жертвой интернет - мошенников выделяют следующие ее качества:

1. корыстолюбие и склонность к риску;

2. чрезмерная доверчивость;

3. внушаемость;

4. правовое и экономическое невежество.

Применительно к интернет - мошенничеству жертвами этих преступлений может стать любой российский гражданин, любого возраста. Однако первое место среди жертв интернет - мошенников занимают дети и подростки, которые в своем юном возрасте стремятся заработать как можно больше денег без особо больших вложений. Молодое поколение активно пользуется сетью «Интернет». На разных интернет ресурсах с помощью разных способов размещается информация о возможном легком заработке, которая в итоге оказывается мошеннической схемой. Не имея большого жизненного и финансового опыта, молодые люди верят этой рекламе, вследствие чего и попадают в руки мошенников. На втором месте жертв интернет мошенников занимают любые азартные люди с низкой финансовой и правовой грамотностью. Они так же, как и молодые люди хотят много и быстро заработать. Вследствие чего они доверяют информации с сомнительных сайтов в сети «Интернет», становясь при этом жертвой [11].

Таким образом, можно сказать о том, что субъективная причина, связанная с личностью потерпевшей стороны, заключается в том что люди сами верят в силу своей финансовой и правовой безграмотности той информации, которую до них доводит интернет мошенник. Не учитывая горький опыт других людей, не изучая отзывы в той же сети «Интернет», например, о той или иной букмекерской конторе или о торговой бирже, граждане участвуют в сомнительной деятельности мошенников.

Государству, на наш взгляд, необходимо активно бороться с этой субъективной причиной. На взгляд множества российских политических деятелей (Колтунов О.А., Орлов С.В., Метлина Н.Б.), самым эффективным средством предупреждения хищения в сфере электронных и финансовых услуг является проведение постоянной разъяснительной работы с населением в виде социальной рекламы по радио, телевидению, в транспорте, в банках и иных местах массового пребывания граждан[12]. Кроме этого, необходимо работать в этом направлении и с молодежью, так как жертвами мошенников в сети «Интернет» зачастую становятся в основном они. Считаем необходимым во всех образовательных организациях общего и высшего образования, пока в качестве факультативных занятий, реализовывать некоторые образовательные программы, которые направлены на развитие финансовой грамотности учеников и студентов. Постоянное повышение финансовой грамотности российских граждан и молодежи позволит минимизировать риски.

Вторая субъективная причина касается личности самого лица, которые совершает мошеннические действия. Криминологические исследования данного рода преступлений говорят о том, что на совершения мошенничества людей толкают экономические причины: безработица, низкая заработная плата, нищета, рост цен и т.д. Однако, не только «бедные» люди идут на обман. Иногда очень даже состоятельные люди становятся мошенниками. Причины, по которым они идут на обман, тоже достаточно разнообразны. Основная причина из них - это жажда легких денег и быстрой наживы без применения особых усилий. Как отмечает Можаева Е.В. одна из характерных особенностей лиц, совершающих мошенничество - это устойчивое стремление к паразитическому образу жизни, отсутствие какой-либо определенной профессии, постоянного места работы, определенного места проживания. Мошенники в большинстве воем - это лица, в основном нигде не работающие либо находящиеся на случайных, фиктивных или временных работах [13].

Таким образом, субъективная причина заключается в том, что вокруг каждого отдельного мошенника складывается определенная экономическая и социальная обстановка, которая толкает его на совершение преступления. В тоже время, граждане, привыкшие к передаче данных по каналам электронной связи, стали достаточно доверчивы, совершая различные действия дистанционно, что способствует деятельности мошенников. 
Подводя итог вышесказанному можно заключить, что юридическая ответственность - это мера государственного принуждения к правонарушителю, установление для него предусмотренных правовыми нормами неблагоприятных последствий за совершенное правонарушение. Интернет-мошенничество - это мошеннические действия, совершаемые посредством виртуальных каналов коммуникации: социальных сетей, в чатах, на веб-сайтах, по электронной почте с целью привлечения потенциальных жертв и проведения мошеннических актов. Любое мошенничество, независимо в какой плоскости оно совершается, обладает рядом признаков: противоправность; изъятие имущества; причинение ущерба потерпевшему лицу; прямой умысел на совершение противоправного деяния; корыстный мотив преступника.

\section{ЛИТЕРАТУРА}

1. Медиахолдинг РБК. [Электронный ресурс] Режим доступа: https://www.rbc.ru/society/31/08/2020/5f48еa169a79477e21e25d9d, свободный (дата 0бращения: 16.05 .2021$)$.

2. Наумов С.Ю. Общая теория государства и права: учебник. — Саратов: Саратовский социально-экономический институт (филиал) Рэу им. Г.В. Плеханова, 2018.- - С. 231.

3. Шабуров А.С. Теория государства и права: учебное пособие — Курган: Изд-во Курганского гос. ун-та, 2019 - С. 344.

4. Рассказов Л.П. Теория государства и права: углубленный курс: Учебник. — М.: РИОР: ИНФРА-М, 2015 — С. 477.

5. Плотников А.И. Уголовное право России. Общая часть: учебник для бакалавров. - Оренбург: 000 ИПК «Университет», 2016 - С. 231.

6. Медиахолдинг РБК. [Электронный ресурс] Режим доступа: https://www.rbc.ru/society/31/08/2020/5f48еa169a79477e21e25d9d, свободный (дата 0бращения: 16.05 .2021$)$.

7. Медиахолдинг РБК. [Электронный ресурс] Режим доступа: https://www.rbc.ru/society/31/08/2020/5f48ea169a79477e21e25d9d, свободный (дата 06ращения: 16.05.2021).

8. Официальный сайт МВД России [Электронный ресурс] Режим доступа: https://мвд.рф/reports/item/23816756/, свободный (дата обращения: 16.05.2021)

9. Официальный сайт Муниципального образования Городской округ Черноголовка. [Электронный ресурс] Режим доступа: http://chgcity.ru/pages/виды-мошенничества-в-сети-интернет-и-причины-их-совершения, свободный (дата обращения: 16.05.2021).

10. Комаров А.А. Неотвратимость уголовной ответственности интернет-мошенников в контексте юрисдикционной проблемы. [Электронный ресурс] Режим доступа: https://web.snauka.ru/issues/2016/09/70952, свободный (дата обращения: 16.05.2021).

11. Майоров А.В. Виктимологический аспект мошенничества // Виктимология. — 2019. — № 3 (21). — С. 36.

12. Официальный сайт Московской городской Думы [Электронный ресурс] Режим доступа: https://dep26.duma.mos.ru/news/20642, свободный (дата 06ращения: 16.05.2021).

13. Можаева Е.В. Мотивация и особенности личности человека, совершившего экономическое мошенничество // Гуманитарные, социально-экономические и общественные науки.— 2014. — № 5-1.- С. 8.

(с Грунина Вероника Александровна ( vgrunvgrun@rambler.ru), 